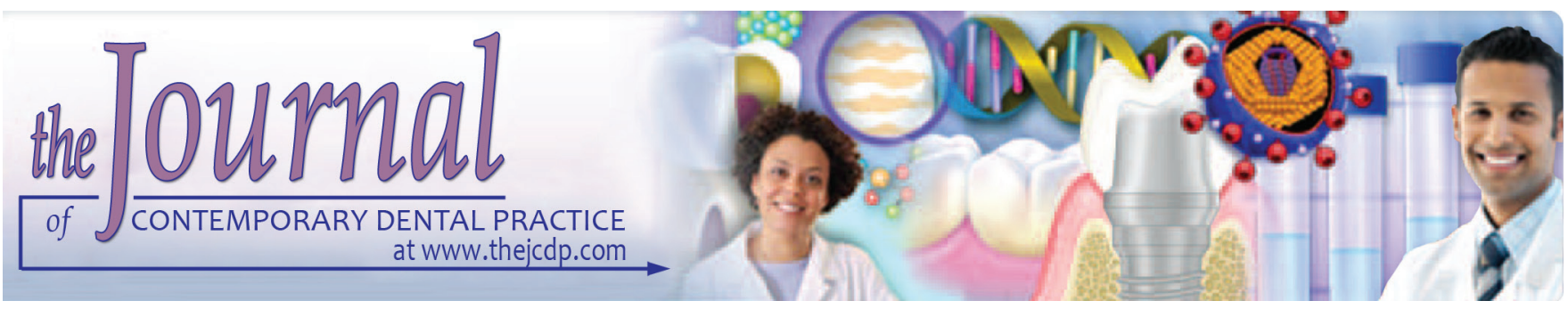

\title{
Epidemiological and Clinicopathological Analysis of 92 Odontogenic Tumors: A 5-year Retrospective Study
}

\author{
${ }^{1}$ Ipsita Sharma, ${ }^{2}$ Deepa Venkatesh, ${ }^{3}$ Geetanjali Bawa, ${ }^{4}$ Syed Vaseemuddin, ${ }^{5}$ Amit Joseph, ${ }^{6}$ Jimmy K Sangtani
}

\begin{abstract}
Introduction: Odontogenic tumors (OTs) are a heterogeneous group of lesions that are derived from odontogenic apparatus comprised of odontogenic epithelium, ectomesenchyme, and/ or mesenchymal elements. The OTs show marked geographical variation. This study was conducted to analyze the epidemiology and clinicopathological presentation of OTs based on age, sex, and site.
\end{abstract}

Materials and methods: This study was conducted in Department of Oral Pathology and Microbiology. Records were reviewed retrospectively for all the lesions of oral cavity from January 2010 to December 2015. A total of 92 lesions were found to be OTs and were classified into benign and malignant tumors. They were further subdivided into three subtypes based on the types of odontogenic tissues involved. These were epithelial OTs (EOTs), mixed OTs (MIXOTs), and mesenchymal OTs (MOTs)

Results: Of 92 OTs, 84 were benign (males 48, females 36 ) and 8 were malignant (male 2 , females 6 ). The most common benign tumor was ameloblastoma (AME) (20), followed by keratocystic OT (KCOT) (17), calcifying EOT (CEOT) (14), compound odontome (OD-Cd) (12), complex odontome (OD-Cx) (10), odontogenic fibroma (OF) (5), odontogenic myxoma

\footnotetext{
${ }^{1}$ Department of Oral Pathology and Microbiology, RKDF Dental College and Research Center, Bhopal, Madhya Pradesh, India

${ }^{2}$ Department of Dentistry, Kodagu Institute of Medical Sciences Madikeri, Karnataka, India

${ }^{3}$ Private Practitioner, Amritsar, Punjab, India

${ }^{4}$ Department of Oral Medicine and Radiology, Dasmesh Institute of Research \& Dental Sciences, Faridkot, Punjab, India

${ }^{5}$ Department of Oral Pathology and Microbiology, DAV Dental College, Solan, Himachal Pradesh, India

${ }^{6}$ Department of Orthodontics, Vidarbha Youth Welfare Society Amravati's Dental College \& Hospital, Amravati, Maharashtra, India

Corresponding Author: Ipsita Sharma, Department of Oral Pathology and Microbiology, RKDF Dental College and Research Center, Bhopal, Madhya Pradesh, India, Phone: +919713546173, e-mail: ipsita2326@gmail.com
}

(OM) (4), and cementoblastoma (CB) (2). The most common malignant tumor was primary intraosseous squamous cell carcinoma (PIOSCC) (3) followed by fibrosarcoma (FS) (3) and ameloblastic carcinoma (AC).

Conclusion: Author concluded that there was geographic and demographic variation in distribution of OTs, which may be attributed to socioeconomic and genetic factors.

Clinical significance: Literature showing prevalence of OTs in India is negligible. By this article, we have analyzed the frequency of various OTs according to sex, age, and site. A comprehensive record of OTs should be started so that pathologists and surgeons would be able to acquire the information about the tumor for reference in the future.

Keywords: Ameloblastoma, Compound odontome, Geographic, Odontogenic tumors.

How to cite this article: Sharma I, Venkatesh D, Bawa G, Vaseemuddin S, Joseph A, Sangtani JK. Epidemiological and Clinicopathological Analysis of 92 Odontogenic Tumors: A 5-year Retrospective Study. J Contemp Dent Pract 2017;18(11):1056-1060.

Source of support: Nil

Conflict of interest: None

\section{INTRODUCTION}

Odontogenic tumors are a group of heterogeneous lesions derived from epithelial or ectomesenchymal tissues or both, which are part of the tooth-forming apparatus. ${ }^{1}$ They occur within the maxillofacial skeleton (intraosseous) or in the gingiva or alveolar mucosa in edentulous regions. These tumors may be generated at any stage in the life of an individual. The World Health Organization (WHO) in 2005 modified the previous classification of OTs and did few changes. Parakeratinized variant of odontogenic keratocyst has been renamed as KCOT. This has been included in benign tumors. Adenoid OT (AOT) has been added in OTs. The WHO mentioned that AOT, which was earlier thought to be arise from ectomesenchyme, was now found to originate from 
odontogenic epithelium with mature fibrous stroma. Calcifying odontogenic cyst (COC) has been divided into two benign forms and one malignant form. They further renamed the clear cell OT as clear cell odontogenic carcinoma (CCOC) which is a malignant lesion. Odontogenic carcinosarcoma has now been excluded from the existing classifications of OTs. ${ }^{2}$ The OTs are rare and comprise $1 \%$ of all biopsied lesions. ${ }^{1}$ There is a geographical variation in prevalence of OTs.

Literature shows that frequency of OTs is mostly among Americans and Africans. Limited studies have been done to evaluate the prevalence of OTs in the Indian subcontinent. Varkhedeet $\mathrm{al}^{3}$ conducted a retrospective study and reviewed 60 cases of OTs from 2001 to 2010 in Indian population. ${ }^{1}$ Okada et $\mathrm{al}^{4}$ reported 226 cases from Sri Lanka. Gupta and Ponniah ${ }^{5}$ conducted a study and analyzed 489 cases in South Indian population. The OTs should be considered in differential diagnosis of jaw lesions.

The present study was conducted to analyze the epidemiology and clinicopathological presentation of OTs as assessed by the WHO 2005 classification based on age, sex, and site. Their occurrence was compared with previous studies.

\section{MATERIALS AND METHODS}

This study was conducted in the Department of Oral Pathology and Microbiology. Records were reviewed retrospectively for all the lesions of oral cavity from January 2010 to December 2015. A total of 92 lesions were found to be OTs and were classified into benign and malignant tumors. They were further subdivided into three subtypes based on the types of odontogenic tissues involved: (1) EOTs, (2) MIXOTs, and (3) MOTs.

Their occurrence according to age, sex, and location was also analyzed. The maxillary and mandibular lesions were divided into two categories based on the radiographic extent.

\section{Class I}

It consisted of lesions limited to the anterior segment of maxilla and mandible, i.e., from distal aspect of right canine to distal aspect of left canine.

\section{Class II}

It consisted of lesions limited to the posterior segment of maxilla and mandible, i.e., from mesial aspect of first premolar distally bilaterally.

Results thus obtained were subjected to statistical analysis using Statistical Package for the Social Sciences version $15.0 ; \mathrm{p}<0.05$ was considered statistically significant.

\section{RESULTS}

A total of 92 OTs were found from January 2010 to December 2015.

Table 1 shows distribution of OTs according to the WHO classification in males and females. Of 92 OTs, 84 were benign (males 48 , females 36 ) and 8 were malignant (male 2, females 6). The most common benign tumor was AME (20), followed by KCOT (17), CEOT (14), OD-Cd (12), OD-Cx (10), OF (5), OM (4), and CB (2). The most common malignant tumor was PIOSCC (3) followed by FS (3) and AC (2).

Table 2 shows distribution of OTs according to age groups. Most OTs were seen in age group of 31 to 40 years followed by 41 to 50 years, 21 to 30 years, 51 to 60 year, 0 to 10 years, and 61 to 70 years.

Ameloblastoma was most commonly seen in fifth decade (8) followed by sixth decade (6), third decade (3), fourth decade (3), third decade (2), and seventh decade (1). KCOT was most commonly seen in fourth decade (6), followed by third decade (5), fifth decade (3), second decade (2), and sixth decade (1). The CEOT was most commonly seen in sixth decade (5), followed by fourth decade (4) and fifth decade (3), and 1 case was seen in both third and seventh decades. The OD-Cx was seen most commonly in second decade (6) followed by third decade (4). The OD-Cd was seen most commonly in the first decade (5) followed by second decade (4), third decade (2), and fourth decade (1). Two cases of OF were seen in third and fourth decades followed by 1 case in second decade. Two cases of OM were seen in second decade, and 1 case was seen each in third and fourth decades. One case of $\mathrm{CB}$ was seen in both fifth and sixth decades. One case of PIOSCC was seen in fourth, fifth, and sixth decades each. Two cases of AC were seen in fifth decade.

Table 1: Distribution of OTs according to gender

\begin{tabular}{llll}
\hline Tumor type & Number & Male & Female \\
\hline Benign & 84 & 48 & 36 \\
EOT & & & \\
$\quad$ AME & 20 & 12 & 8 \\
$\quad$ KCOT & 17 & 8 & 9 \\
$\quad$ CEOT & 14 & 8 & 6 \\
MIXOT & & & \\
$\quad$ Complex odontoma & 10 & 7 & 3 \\
$\quad$ Compound odontoma & 12 & 8 & 4 \\
MOT & & & \\
$\quad$ OF & 5 & 3 & 2 \\
$\quad$ OM/myxofibroma & 4 & 2 & 2 \\
$\quad$ CB & 2 & 0 & 2 \\
Malignant tumors & 8 & 2 & 6 \\
$\quad$ PIOSCC & 3 & 1 & 2 \\
AC & 2 & 0 & 2 \\
FS & 3 & 1 & 2 \\
\hline Total & 92 & 50 & 42 \\
\hline
\end{tabular}


Table 2: Distribution of OTs according to age

\begin{tabular}{|c|c|c|c|c|c|c|c|}
\hline \multirow[b]{2}{*}{ Tumor } & \multicolumn{7}{|c|}{ Age groups (in years) } \\
\hline & $0-10$ & $11-20$ & $21-30$ & $31-40$ & $41-50$ & $51-60$ & $61-70$ \\
\hline AME & & & 2 & 3 & 8 & 6 & 1 \\
\hline KCOT & & 2 & 5 & 6 & 3 & 1 & \\
\hline CEOT & & & 1 & 4 & 3 & 5 & 1 \\
\hline Complex odontoma & & 6 & 4 & & & & \\
\hline Compound odontoma & 5 & 4 & 2 & 1 & & & \\
\hline OF & & 1 & 2 & 2 & & & \\
\hline OM/myxofibroma & & 2 & 1 & 1 & & & \\
\hline CB & & & & & 1 & 1 & \\
\hline PIOSCC & & & & 1 & 1 & 1 & \\
\hline$A C$ & & & & & 2 & & \\
\hline FS & & & & 2 & 1 & & \\
\hline Total & 5 & 15 & 17 & 20 & 19 & 14 & 2 \\
\hline
\end{tabular}

Two cases of FS were seen in fourth decade, and 1 case was seen in fifth decade.

\section{DISCUSSION}

Numerous studies have been performed depicting the OTs in various countries, but very less literature is available in Asian, especially in Indian, subcontinent. We conducted a study in the Department of Oral Pathology and Microbiology. Records were reviewed retrospectively for all the lesions of oral cavity from January 2010 to December 2015. A total of 92 lesions were found to be OTs and were classified into benign and malignant tumors. They were further subdivided into three subtypes based on the types of odontogenic tissues involved: EOTs, MIXOTs,, and MOTs. In this study, we followed the WHO classification and we classified OTs accordingly. We identified 92 OTs out of which, 84 were benign and 8 were malignant. Lesions that present aggressive biologic behavior, such as AMEs represent a considerable number of the OTs. It constituted $21.7 \%$ of all OTs.

The most common benign tumor was AME (20), followed by KCOT (17) and CEOT (14). The AME was most commonly seen in mandible, and there was male predilection. Posterior mandible was involved in most of the cases. It was most commonly seen in fifth and sixth decades of life. Our study is in agreement with study conucted by Avelar et $\mathrm{al}^{6}(23.7 \%)$ and Gaitán-Cepada et $\mathrm{al}^{7}(19.3 \%)$, whereas studies of Tawfik and Zyada ${ }^{8}$ and Varkhede et $\mathrm{al}^{9}$ reported higher incidence.

The KCOT $(18.5 \%)$ was the second most OT reported in our study. Female predilection was seen in our study. Our results are similar to the study conducted by Tawfik and $\mathrm{Zyada}^{8}$ who reported $19.5 \%$ of KCOT. Various authors have reported higher incidences. ${ }^{10,11}$ It was seen mostly in fourth and fifth decades with posterior mandible predominance. We reported 14 cases of CEOT $(15.2 \%)$. Most were seen in posterior mandible and in fourth and sixth decades of life (Table 3 ). The prevalence was higher than that reported earlier by various authors. The prevalence recorded by Tamme et $\mathrm{al}^{12}$ was $1.3 \%$ and by Arotiba et $\mathrm{al}^{13}$ was $1.6 \%$.

Odontomes were seen in 22 cases. The difference was significantly higher than the results of Jing et al $(4.5 \%$; $\mathrm{p}=0.001)$. Zhu et $\mathrm{al}^{14}$ in their study reported $28.4 \%$ of

Table 3: Distribution of OTs according to site

\begin{tabular}{|c|c|c|c|c|c|c|}
\hline \multirow[b]{2}{*}{ Tumor } & \multicolumn{3}{|c|}{ Maxilla } & \multicolumn{3}{|c|}{ Mandible } \\
\hline & Total & Class I & Class II & Total & Class I & Class II \\
\hline AME & 4 & 1 & 3 & 16 & 4 & 12 \\
\hline KCOT & 2 & 0 & 2 & 15 & 3 & 12 \\
\hline CEOT & 2 & 1 & 1 & 12 & 2 & 10 \\
\hline Complex odontoma & 4 & 1 & 3 & 6 & 2 & 4 \\
\hline Compound odontoma & 8 & 6 & 2 & 4 & 3 & 1 \\
\hline OF & 1 & 0 & 1 & 4 & 1 & 3 \\
\hline OM/myxofibroma & 1 & 1 & 0 & 3 & 0 & 3 \\
\hline $\mathrm{CB}$ & 0 & 0 & 0 & 2 & 0 & 2 \\
\hline PIOSCC & 0 & 0 & 0 & 3 & 1 & 2 \\
\hline$A C$ & 0 & 0 & 0 & 2 & 0 & 2 \\
\hline FS & 0 & 0 & 0 & 3 & 0 & 3 \\
\hline Total & 22 & 10 & 12 & 70 & 16 & 54 \\
\hline
\end{tabular}


Epidemiological and Clinicopathological Analysis of 92 Odontogenic Tumors

Table 4: Comparison of present study with various studies

\begin{tabular}{|c|c|c|c|c|c|c|c|}
\hline Tumor & $\begin{array}{l}\text { Our study } \\
2015\end{array}$ & Avelar et al ${ }^{6}$ & $\begin{array}{l}\text { Gaitán- } \\
\text { Cepada et al }\end{array}$ & $L u o$ and $L i^{19}$ & Jing et $a l^{18}$ & $\begin{array}{l}\text { Tawfik and } \\
\text { Zyada }^{8}\end{array}$ & $\begin{array}{l}\text { Varkhede } \\
\text { et al }\end{array}$ \\
\hline AME & 21.7 & 23.7 & 19.3 & 36.5 & 40.3 & 41.5 & 40.83 \\
\hline KCOT & 18.5 & 30 & 38.9 & 38.7 & 35.8 & 19.5 & 37.5 \\
\hline CEOT & 15.2 & 2 & 1.4 & 0.46 & 0.6 & 3.7 & 0.83 \\
\hline Complex odontoma & 10.8 & 22.1 & 6 & 5.18 & 4.5 & 13.5 & 10.12 \\
\hline Compound odontoma & 13 & 20 & 4 & 6.11 & 4.7 & 11.5 & 11.67 \\
\hline OF & 5.4 & - & 1 & 1.60 & 0.3 & - & - \\
\hline OM/myxofibroma & 4.3 & - & 2 & 1 & 1 & - & - \\
\hline CB & 2.1 & 1.7 & - & 1.68 & 2 & 3.7 & 0.83 \\
\hline PIOSCC & 3.2 & - & - & 3.74 & 0.9 & 2.4 & - \\
\hline$A C$ & 2.17 & - & - & 1.3 & 1.6 & - & - \\
\hline FS & 3.2 & - & - & - & 2 & - & - \\
\hline Total & & & & & & - & \\
\hline
\end{tabular}

odontomes. Higher frequency of OD in anterior maxilla was consistent with the findings of Mosqueda-Taylor et $\mathrm{al}^{15}$. Relatively high frequencies of OD were in agreement with those of Tawfik and Zyada. ${ }^{8}$ Odontogenic fibroma was seen in $5.4 \%$ of OTs. This is in agreement with the results of Daley et al. ${ }^{16}$ The incidence is significantly higher than that reported by Adebayo et $\mathrm{al}^{17}(\mathrm{p}=0.01)$. Odontogenic myxoma was seen in $4.3 \%$ of cases, whereas study by Mosqueda-Taylor et $\mathrm{al}^{15}$ reported $18.3 \%$ of cases. The CB was observed in $2.1 \%$ of cases. Result agrees with those of Jing et $\mathrm{al}^{18}(2.9 \%)$.

The most common malignant tumor was PIOSCC (3.2\%), which is in accordance with Luo and Li. ${ }^{19}$ Incidence of AC was $2.17 \%$, and FS was seen in $3.2 \%$ of cases.

Our results were in contrast to the results obtained by da-Costa et $\mathrm{al}^{20}$ who assessed the incidence of OTs in Brazil. They reevaluated the tumors, which were diagnosed and classified according to the WHO classification given in 2005. They analyzed a total of 15,758 biopsies and observed that $1.3 \%$ of them were OTs. In their study, keratocytic OT was the most commonly found OT. Peker et $\mathrm{al}^{21}$ presented the incidence and pattern of distribution of jaw lesion reported in the Department of Oral Pathology of Faculty of Dentistry from 2008 to 2013. They analyzed a total of 1,938 biopsies and included a total of 1,473 lesions in their study. On comparing the provisional and hisotpathologic diagnosis, they observed that 96 lesions were developmental/reactive and inflammatory lesions of the jaw. However, they found disagreement of clinical and hisotpathologic diagnosis in 29 biopsied lesions. Spatafore et $\mathrm{al}^{22}$ reviewed biopsy specimens from the apices of over 1,600 teeth and observed that granulomas comprised majority of the lesions (Table 4).

\section{CONCLUSION}

Author concluded that there was geographic and demographic variation in distribution of OTs, which may be attributed to socioeconomic and genetic factors. Our study revealed few facts that benign OTs were more common than malignant OTs in almost all parts of the world. Ameloblastoma, KCOT, CEOT, and odontoma were the most common tumors. The incidence of CEOT was significantly higher than in other studies. Very few studies have been done in India so far. Hence, large-scale studies are needed in the future to substantiate the results obtained in this study.

\section{REFERENCES}

1. Sriram G, Shetty RP. Odontogenic tumors: a study of 250 cases in an Indian teaching hospital. Oral Surg Oral Med Oral Pathol Oral Radiol Endod 2008 Jun;105(6):e14-e21.

2. Ebenezer V, Ramalingam B. A cross-sectional survey of prevalence of odontogenic tumours. J Maxillofac Oral Surg 2010 Dec;9(4):369-374.

3. Varkhede A, Tupkari JV, Mandale MS, Sardar M. Odontogenic tumors: a review of 60 cases. J Clin Exp Dent 2010 Jul;2(4):e183-e186.

4. Okada H, Yamamoto H, Tilakaratne WM. Odontogenic tumors in Sri Lanka: analysis of 226 cases. J Oral Maxillofac Surg 2007 May;65(5):875-882.

5. Gupta B, Ponniah I. The pattern of odontogenic tumors in a government teaching hospital in the Southern Indian state of Tamil Nadu. Oral Surg Oral Med Oral Pathol Oral Radiol Endod 2010 Jul;110(1):e32-e39.

6. Avelar RL, Antunes AA, Santos Tde S, Andrade ES, Dourado E. Odontogenic tumors: clinical and pathology study of 238 cases. Braz J Otorhinolaryngol 2008 Sep-Oct;74(5):668-673.

7. Gaitán-Cepeda LA, Quezada-Rivera D, Tenorio-Rocha F, Leyva-Huerta ER. Reclassification of odontogenic keratocyst as tumour. Impact on the odontogenic tumours prevalence. Oral Dis 2010 Mar;16(2):185-187.

8. Tawfik MA, Zyada MM. Odontogenic tumors in Dakahlia, Egypt: analysis of 82 cases. Oral Surg Oral Med Oral Pathol Oral Radiol Endod 2010 Feb;109(2):e67-e73.

9. Varkhede A, Tupkari JV, Sardar M. Odontogenic tumors: a study of 120 cases in an Indian teaching hospital. Med Oral Patol Oral Cir Bucal 2011 Nov;16(7):e895-e899.

10. Fernandes AM, Duarte EC, Pimenta FJ, Souza LN, Santos VR, Mesquita RA, de Aguiar MC. Odontogenic tumors: a study 
of 340 cases in a Brazilian population. J Oral Pathol Med 2005 Nov;34(10):583-587.

11. Buchner A, Merrell PW, Carpenter WM. Relative frequency of central odontogenic tumors: a study of 1,088 cases from Northern California and comparison to studies from other parts of the world. J Oral Maxillofac Surg 2006 Sep;64(9):1343-1352.

12. Tamme T, Soots M, Kulla A, Karu K, Hanstein SM, Sokk A, Jõeste E, Leibur E. Odontogenic tumours, a collaborative retrospective study of 75 cases covering more than 25 years from Estonia. J Craniomaxillofac Surg 2004 Jun;32(3):161-165.

13. Arotiba JT, Ogunbiyi JO, Obiechina AE. Odontogenic tumours: a 15-year review from Ibadan, Nigeria. Br J Oral Maxillofac Surg 1997 Oct;35(5):363-367.

14. Zhu E, Fang J, Okada N. Clinical statistics of odontogenic tumors. Shika J 1993;37:555.

15. Mosqueda-Taylor A, Ledesma-Montes C, Caballero-SandovalS, Portilla-Robertson J, Ruíz-Godoy Rivera LM, MenesesGarcía A. Odontogenic tumors in Mexico: a collaborative retrospective study of 349 cases. Oral Surg Oral Med Oral Pathol Oral Radiol Endod 1997 Dec;84(6):672-675.

16. Daley TD, Wysocki GP, Pringle GA. Relative incidence of odontogenic tumors and oral and jaw cysts in a
Canadian population. Oral Surg Oral Med Oral Pathol 1994 Mar;77(3):276-280

17. Adebayo ET, Ajike SO, Adekeye EO. A review of 318 odontogenic tumors in Kaduna, Nigeria. J Oral Maxillofac Surg 2005 Jun;63(6):811-819.

18. Jing W, Xuan M, Lin Y, Wu L, Liu L, Zheng X, Tang W, Qiao J, Tian W. Odontogenic tumours: a retrospective study of 1642 cases in a Chinese population. Int J Oral Maxillofac Surg 2007 Jan;36(1):20-25.

19. Luo HY, Li TJ. Odontogenic tumors: a study of 1309 cases in a Chinese population. Oral Oncol 2009 Aug;45(8):706-711.

20. da-Costa DO, Maurício AS, de-Faria PA, da-Silva LE, Mosqueda-Taylor A, Lourenço SQ. Odontogenic tumors: a retrospective study of four Brazilian diagnostic pathology centers. Med Oral Patol Oral Cir Bucal 2012 May;17(3):e389-e394.

21. Peker E, Ögütlü F, Karaca IR, Gültekin ES, Çakir M. A 5 year retrospective study of biopsied jaw lesions with the assessment of concordance between clinical and histopathological diagnoses. J Oral Maxillofac Pathol 2016 Jan-Apr;20(1): 78-85.

22. Spatafore CM, Griffin JA Jr, Keyes GG, Wearden S, Skidmore AE. Periapical biopsy report: an analysis of over a 10-year period. J Endod 1990 May;16(5):239-241. 